\title{
Comparison of nest-building materials in farrowing crates
}

\author{
Swan, Kirsi-Marja
}

2018-06

Swan , K-M , Peltoniemi , O A T , Munstherjelm , C \& Valros , A 2018 , ' Comparison of nest-building materials in farrowing crates ' , Applied Animal Behaviour Science, vol. 203 , pp. 1-10 . https://doi.org/10.1016/j.applanim.2018.02.008

http://hdl.handle.net/10138/298988

https://doi.org/10.1016/j.applanim.2018.02.008

cc_by_nc_nd

acceptedVersion

Downloaded from Helda, University of Helsinki institutional repository.

This is an electronic reprint of the original article.

This reprint may differ from the original in pagination and typographic detail.

Please cite the original version. 


\section{Accepted Manuscript}

Title: Comparison of nest-building materials in farrowing crates

Authors: Kirsi-Marja Swan, Olli Aarno Tapio Peltoniemi, Camilla Munstherjelm, Anna Valros

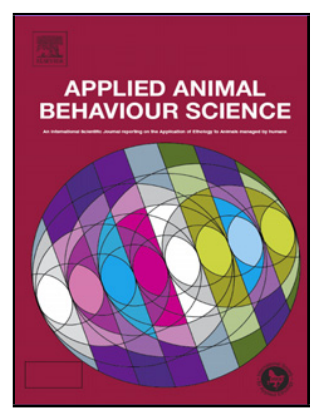

PII: S0168-1591(18)30072-8

DOI: https://doi.org/10.1016/j.applanim.2018.02.008

Reference: APPLAN 4603

To appear in:

APPLAN

Received date: 23-7-2017

Revised date: $17-12-2017$

Accepted date: $11-2-2018$

Please cite this article as: Swan, Kirsi-Marja, Peltoniemi, Olli Aarno Tapio, Munstherjelm, Camilla, Valros, Anna, Comparison of nestbuilding materials in farrowing crates.Applied Animal Behaviour Science https://doi.org/10.1016/j.applanim.2018.02.008

This is a PDF file of an unedited manuscript that has been accepted for publication. As a service to our customers we are providing this early version of the manuscript. The manuscript will undergo copyediting, typesetting, and review of the resulting proof before it is published in its final form. Please note that during the production process errors may be discovered which could affect the content, and all legal disclaimers that apply to the journal pertain. 
Comparison of nest-building materials in farrowing crates

Swan, Kirsi-Marja ${ }^{a^{*}}$, Peltoniemi Olli Aarno Tapio ${ }^{b}$, Munsterhjelm Camilla ${ }^{a}$, Valros Anna ${ }^{a}$

${ }^{a}$ Research Centre for Animal Welfare, Department of Production Animal Medicine, Faculty of Veterinary Medicine, University of Helsinki, P.O. Box 57, 00014 Helsinki, Finland

${ }^{\mathrm{b}}$ Department of Production Animal Medicine, Faculty of Veterinary Medicine, University of Helsinki, Paroninkuja 20, 04920 Saarentaus, Finland

${ }^{*}$ Corresponding author. Tel.:+358-50-4156656, fax: +358-9 194 57300, E-mail address: kirsi.swan@helsinki.fi

Highlights

- Offering suitable nest-building material, even to sows in crates, leads to higher nest-building activity.

- Peripartal behaviour of the sows is stimulated differently by different nest-building materials.

- Stimulation of sow peripartal behaviour may impact upon sows behaviour, piglet performance and welfare.

\section{Abstract}

The farrowing crate restricts the performance of natural behaviour of sows, such as nest building, by limiting both sow movement and use of suitable nest-building materials. Restriction leads to short- and long lasting changes in farrowing, maternal behaviour and lactation. We investigated the effects of the provision of a variety of nest-building materials in a restricted farrowing environment on sow behaviour, the course of farrowing, saliva cortisol concentrations and piglet performance. The study was carried out in two parts. In the first phase six materials were either attached to the farrowing crate or offered in amounts of $1-2$ litres in front of the sows $(n=40)$ : Object on the ground, Object on the side, Wood shavings, Straw, Shredded paper and Newspaper. Video recordings of sow behaviour were analysed from 12 hours prepartum until the sixth piglet of each 
litter was born. No differences in sow behaviour between the treatments were found. The results and functionality of the materials entailed that straw, wood shavings and newspaper were investigated further in second phase of our investigation. Data on the mortality of the piglets were collected by the farmer ( $\mathrm{n}=199$ litters), post mortem examinations were performed on all dead piglets of 66 litters. Video recordings were analysed for pre- and peripartum behaviour $(n=19)$, salivary cortisol samples were collected twice daily and analysed from days -2 to +2 pre- and postpartum $(n=47)$. Mean litter weights were determined on days 2, 4, 6 and at weaning $(n=55)$. The newspaper group performed more nest-building $(p=0.04)$ and less bar-biting $(p<0.001)$ activities than the straw and the wood shavings groups. Mortality during lactation was lower in the straw group than in the other groups during the entire lactation period $(p<0.001)$, and lower in the straw group than in the wood shavings group during the first three days of lactation $(p<0.001)$. No differences in cortisol concentrations, piglet weight gain or in the course of farrowing were found. We conclude that different nesting materials stimulate sow peripartal behaviour differently, which in turn could impact upon sows behaviour, piglet performance and welfare.

Keywords: sow; farrowing; nest-building; bar-biting; piglet mortality

1. Introduction

The sow is a strongly motivated to build a nest before farrowing regardless of the facilities provided (Widowski and Curtis, 1990). Restriction of the sow's ability to perform nest-building causes stress (Damm et al., 2003; Vestergaard and Hansen 1984) which leads to unfavourable peripartal endocrinological changes and affects the course of farrowing (Oliviero et al., 2008; Thodberg et al., 2002). European Union legislation stipulates that sows and gilts must be given suitable nesting material and all pigs must be given appropriate material to satisfy their behavioural needs (Council of European Union, 2008). 
The most common farrowing environment used in western countries is a fully slatted farrowing pen equipped with a farrowing crate (Barnett et al., 2001; Johnson and Marchant-Forde, 2009).

According to producers, offering material is often impractical due to the slurry management system used on the premises. Few studies have compared different nest-building materials in farrowing crates, whereas most studies on nest-building materials have been done in pens. Both the choice of material (Yun et al., 2013) and space allowance (Jarvis et al., 2004) impact upon the periparturient behaviour of the sow.

Nest-building is most intensive in the 12-4 hour period before the birth of the first piglet (Damm et al., 2003; Oliviero et al., 2008; Vestergaard and Hansen, 1984; Widowski and Curtis, 1990; Yun et al., 2014). Several endocrine changes are related to nest-building, including changes in prostaglandin, prolactin, progesterone and somatostatin levels (Algers and Uvnäs-Moberg, 2007). A rise in oxytocin (Castrén et al., 1993) and of udder comfort (Baxter, 1983) are considered to terminate the nest-building behaviour. The behaviour itself and the outcome, a functional nest, are important components of the satisfactoral completion of nest building (Castrén et al., 1993; Damm et al., 2000; Thodberg et al., 1999). If there is no suitable material available for nest-building, the sow will redirect her behaviour towards available structures by carrying out activities such as barbiting, which is considered to be abnormal behaviour (Yun et al., 2015). This does not, however, compensate for the lack of material (Jarvis et al., 2001; Lammers and De Lange, 1986; Widowski and Curtis, 1990).

Plasma cortisol increases in acute stressful situations, such as during antagonistic interactions with other animals (Otten et al. 2010, 1997) or during tethering (Janssens et al., 1995). Parturition itself is a stressor for the sow as indicated by a rise in cortisol levels, which has been shown to increase even more for crated sows compared to penned sows (Lawrence et al., 1994). Restriction of nestbuilding in crates leads to stress, frustration, behavioural changes (Damm et al., 2003; Vestergaard and Hansen, 1984) and physiological changes, such as hypothalamic-pituitary-adrenal (HPA) axis activation. The HPA activation leads to higher blood cortisol concentrations (Lawrence et al., 1994), which are maintained through early lactation in crated sows (Oliviero et al., 2008). 
Frustration develops partly because of poor feedback from an incomplete nest and this prolongs the farrowing especially in primiparous sows (Thodberg et al., 2002, 1999). This is suggested to be a consequence of the stress reaction inhibiting the release of oxytocin (Oliviero et al., 2008). On the other hand, high plasma oxytocin concentration is considered to terminate the nest-building behaviour earlier in relation to parturition (Castren et al., 1993). Prolactin is considered to trigger the onset of nest-building and it is found in higher concentrations when nest-building material is available to sows (Castrén et al., 1993). Prolactin concentrations correlate positively with oxytocin concentrations and it might therefore have a role in the course of farrowing (Yun et al., 2013). The sows ability to provide maternal care after farrowing can be compromised by frustration and low prolactin levels (Herskin et al., 1998; Pedersen et al., 2003; Thodberg et al., 1999), which in turn affects piglet suckling behaviour (Pedersen et al., 2003), weight gain (IIImann et al., 2015) and mortality (Andersen, 2005; Westin et al., 2015).

Sow behaviour seems to be stimulated differently by different materials and sows prefer certain materials for nest-building (Widowski and Curtis, 1990). For example, straw elicits more nestbuilding and also affects farrowing behaviour positively when compared to sand (Thodberg et al., 1999). Some studies have shown that long-stemmed straw promotes nest-building more than chopped straw (Burri et al., 2009; Mainau et al., 2010), whereas Damm et al. (2005) found no effect of straw length on peripartal behaviour. Greater amounts of straw has also been shown to stimulate nest-building behaviour (Westin, 2014). Sows that had been provided with wood shavings prior to farrowing performed prepartal nest-building for longer, and had more postural changes during farrowing than sows that had been provided with straw (Chaloupková et al., 2014). Sows tended to choose a pen bedded with straw rather than a pen with sawdust bedding before farrowing (Arey, 1997). Straw has also been shown to be favoured over a cloth tassel, although animals did use the tassel when no straw was available (Widowski and Curtis, 1990).

The objectives of this study were to compare different nest-building materials suitable for use in modern farrowing crates. We tested commonly used materials in pig farming to evaluate which was the best nesting-material to use for sows in a commercial environment. We hypothesized that the 
more the sows direct nets-building behaviour towards the material offered, the less they will express redirected behaviour in the form of bar-biting, the lower will be the cortisol level of the sow, the easier will be the course of farrowing and the better will be the survival of the piglets.

\section{Materials and methods}

Approval for the study was obtained from the Ethics Committee of Viikki Campus of the University of Helsinki, Finland.

\subsection{Housing and management}

The studies were carried out on a commercial piglet-producing health approved weaner farm that is situated in Central Finland. The herd had about 400 sows, mainly crossbred. During gestation animals were housed in peat-bedded pens in groups of 8-10.

The farrowing unit was divided into four compartments. Each compartment contained 20 farrowing crates with plastic slatted floors and a solid creep area with floor heating for the piglets (Diagram 1). An oat-barley-wheat diet (Emakko Pekoni®, Suomen Rehu, Finland, NE 12.05 MJ/kg, crude protein $15,5 \%, 2-2.9 \mathrm{~kg} /$ day) was given three times daily at 7:00 h, 12:00 h and 17:00 h. Drinking water was freely available. The lights were kept on between 7:00-16:00 h and temperature was regulated to the $18-21^{\circ} \mathrm{C}$ range. All the sows farrowed without hormonal induction. 


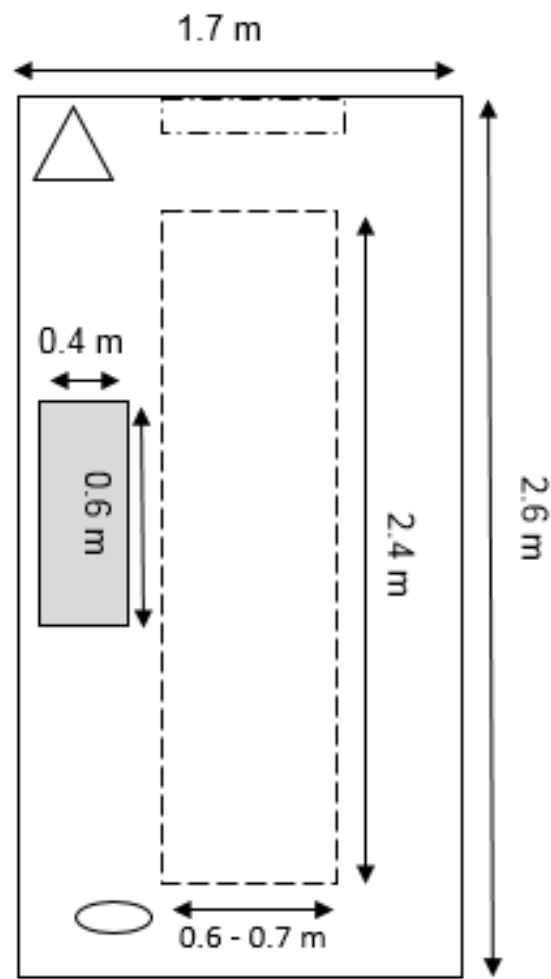

Farrowing crate -.......

Trough ---

Heated solid creep area $\square$

Heat lamp o Camera $\triangle$

Diagram 1 Schematic diagram of the farrowing pen 


\subsection{General study design and selection of animals}

Sows that had been selected for the experiments were randomly divided into six experimental groups. The selection took place when sows were moved to the farrowing unit 2- 6 days before the expected farrowing, which was calculated as 116 days from the date of insemination. Sows were excluded when any clinically observable illness was detected. The body condition score of each sow was determined. The body condition score is based on a scale of 1 to 5 , with $1=$ very thin and $5=$ very fat (Hulsen and Scheepens, 2006). Only sows with score $2-4$ were included in the study. We selected materials with different qualities based on a brief questionnaire sent to farmers $(n=$ 30) and veterinarians $(n=13)$ in Finland. The selection and qualities of the materials are presented in Table 1.

Cross-fostering did not occur in the first phase of the study (PILOT), surplus piglets were removed and fostered onto a sow outside the experiment. In contrast cross-fostering was performed in the second phase (STUDY) within the first 24 hours after birth. Piglets were either moved onto sows from the same treatment, or onto sows not participating in the STUDY phase of this investigation. The number of piglets cross-fostered were 115 piglets from 27 litters for the newspaper group, 87 piglets from 25 litters for the straw group and 80 piglets from 25 litters of the wood shavings group. European legislation (Council of the European Union, 2008) and Finnish regulation (Ministry of Agriculture and Forestry, 2002) stipulate that the sow must to be provided with suitable nestbuilding material. Consequently there was no control group without nest-building material included in the study.

\subsection{Study design part 1 (PILOT)}

The aim of the PILOT phase of the investigation was to get preliminary information on a number of different potential nest-building materials in order to evaluate them in the main phase of the investigation (STUDY).

Fifty-seven sows with parity 2 or above were selected for the PILOT. Four of the sows were excluded from the experiment: two of them farrowed before the material was given, one sow did not farrow during the video recordings and the fourth sow continually escaped from the crate. 
Sows were divided into six groups. Five of the groups were given nonglossy newsprint paper plus one other extra nest-building material (Table 1), sixth group served as a reference group, and got only newspaper, which was the nest-building material that was regularly used on this farm.

Sample sizes are given in Table 2.

Apart from the 'object on the ground' and the 'object on the side groups' (Table 1), nest-building materials were given three times a day at 8:00- 9:00 h, 13:00- 14:00 $\mathrm{h}$ and 20:00-22:00 $\mathrm{h}$ starting on the day after sows arrived at the farrowing unit. If there was clean material left in the pen it was collected and placed in front of the sow and fresh material was added up to the amount required to fill the 2-3I volume as per protocol. The side-objects and the ground-objects were reattached and replaced when needed. Dirty or wet material was removed and replaced by fresh material.

All the sows were video recorded continuously, which started three days before the expected farrowing and ended when the farrowing was considered to be completed.

Wireless video cameras (NiceCAM420WL fitted with $3.6 \mathrm{~mm}$ lens) run on Blue Iris $^{\mathrm{TM}}$ software $^{-1}$ (Perceptive Software, USA) were attached above the pen on the fixed structures of the unit on the head-end, which provided a view of the whole pen with the farrowing crate (Picture 1).The camera was installed on the same side as the object for the object on the side group.

Data on the performance of the litters, including the number of piglets born, number of stillborn piglets and piglet mortality were collected by the farmer.

\subsection{Study design part 2 (STUDY)}

As there was no clear differences between the materials in the PILOT (see section 3.3.1.) we chose three materials: straw, newspaper and wood shavings, based on characteristics such as availability, usefulness, price and the opinion of the farmer.

In total 208 sows and gilts were assigned to the treatment groups. Sample sizes varied between the different study-parameters and are presented in table 2. 
Newspaper was given to the newspaper group exclusively. All the groups were given a $40 \mathrm{~cm}$ long metal chain with nine plastic discs of $7 \mathrm{~cm}$ diameter between the chain parts, which was attached to the side of the farrowing crates. Manipulation of the chain was considered to be the equivalent of bar-biting.

Saliva samples for cortisol analysis were collected twice daily before feeding at 10:00 $\mathrm{h}$ and 14:00 h into Salivette ${ }^{\circledR}$ tubes (Sarested AG \& Co., Germany). The cortisol sampling started two days before the expected farrowing ( $D-2)$ and ended on the second day after farrowing $(D+2)$. The Salivette ${ }^{\circledR}$ tubes contain a cotton swab which was held in the mouth of the sow until the swab was wet with saliva. Collecting the saliva took approximately 2 minutes per sow. The swab was then placed back in to the tube and centrifuged at $3500 \mathrm{rpm}$ for $10 \mathrm{~min}$. The volume of saliva was approximately $1.5-2 \mathrm{ml}$ per sample and this was frozen and stored at $-20^{\circ} \mathrm{C}$ until analysis.

A subset of the sows used for cortisol sampling were video recorded pre- and peripartum, and the litter weight was determined on days 2, 4, 6 and at weaning. Piglets that died before weaning were collected in a separate bucket for each sow and stored in a cooled container. Post mortems were carried out as soon as possible, and no later than $48 \mathrm{~h}$ after death. The cause of death was determined on the farm by trained researchers according to the criteria presented in Table 3.

\subsection{Behavioural observations}

Behavioural observations were made using Observer XT 10 ${ }^{\circledR}(\bigodot$ Noldus Information Technology) based on the ethogram presented in Table 4. Observation of the videos started at $12 \mathrm{~h}$ before the first piglet was born (12BFP). According to Pedersen et al. (2003) and Jarvis et al. (1999) the sow is most active at the beginning of farrowing. We took this finding into consideration and ended the observation after the $6^{\text {th }}$ (PILOT) or $8^{\text {th }}$ (STUDY) piglet born (DUR6 and DUR8).

The observation in the PILOT phase was done for 20 s every 5 min. In the STUDY the observations were run continuously. 
Reports of the mean duration of uncomplicated farrowing in crates in earlier studies vary from 166 to 270 minutes (Chaloupková et al., 2014; van Dijk et al., 2005; Mainau et al., 2010; Oliviero et al., 2008; Thodberg et al., 2002) and the birth interval has been found to be in the 15- 40 minutes range (Mainau et al., 2010; Oliviero et al, 2008; Thodberg et al., 2002). We used these findings in our study design to determine the dystocia criteria and thus considered a farrowing to be dystocic when the interval between two piglets was more than $120 \mathrm{~min}$ (DYS2) or when the overall farrowing time of piglets was more than 480 min (DYS8) or when the farrowing was intervened in by the stockperson who judged that the sow required help in farrowing.

\subsection{Cortisol Analyses}

Salivary cortisol was determined by radioimmunoassay (Spectria ${ }^{\circledR}$ Cortisol RIA, Orion Diagnostica, Finland). The test was validated to measure cortisol in pig saliva as described in (Oliviero et al., 2008) and performed as instructed by the manufacturer. A150 $\mu$ volume of saliva and $500 \mu \mathrm{l}$ of buffered ${ }^{125}$ were mixed in tubes whose internal surfaces were coated with antibodies raised against cortisol. Incubation took place in a water bath at $37^{\circ} \mathrm{C}$ for $30 \mathrm{~min}$. After incubation the saliva was decanted off and discarded and the tubes washed with distilled water. A gamma counter (Clinigamma 1272 LKB Wallace, Turku, Finland) was used to measure the radioactivity in the tubes for $1 \mathrm{~min}$. The intra- and inter- assay coefficient of variations were $7.3-7.8 \%$ and $4.9-$ $13.5 \%$, respectively. The lower detection limit of the cortisol assay was $0.36 \mathrm{ng} / \mathrm{ml}$.

\subsection{Statistical analyses}

Statistical analyses was performed using IBM SPSS Statistics for Windows, version 24.0 (IBM Corporation, Armonk, NY, released 2015).

The behavioural data of the before the birth of the first piglet was summarized for two time periods: $12 \mathrm{~h}(12 \mathrm{BFP})$ and $2 \mathrm{~h}$ (2BFP). Data during farrowing was summarized for DUR 6 (PILOT) or DUR8 (STUDY).

The variables were tested for normality using the Kolmogorov-Smirnov test. Most of the variables were not normally distributed, thus non-parametric tests were used. 
The difference in parity, body condition score and total number of piglets born between the treatments were analysed by independent samples Kruskal-Wallis test. The Kruskal-Wallis test was also used to analyse behaviour between the treatments, occurrence of dystocia and mortality of the piglets.

The Spearman Rank Order Correlation Coefficients $\left(r_{s}\right)$ with two-tailed test of significance $(p)$ was used to analyse relationships between nest-building, bar-biting and other behavioural activities. Results are presented only when the strength was found to be moderate to very strong $\left(r_{s}=0.5-\right.$ 1.0) and the correlation between the parameters were determined in both phases of the investigation i.e. PILOT and STUDY respectively.

In the STUDY phase bar-biting and nest-building 12BFP by hour were subjected to Friedmans's test of differences among repeated measurements. A chi-squared test of independence was performed to examine the relation between nest-building material treatment and the result of pathological examination.

The effect of treatment on cortisol measured in saliva (mean per day) and litter weight were subjected to analysis of variance (ANOVA) with repeated measurement.

Results were considered statistically significant for $p<0.05$. Only statistically significant results are shown.

3. Results

3.1. Characteristics of the animals

3.1.1. PILOT phase

Median parity of the sows was $4(2-8, n=53)$. Parity did not differ between treatment groups nor did a median body condition score of $3(2-4)$, total median number of piglets born $13(2-19)$ or total median number of stillborn piglets $1(0-13)$.

\subsubsection{STUDY phase}


Median parity of all 208 sows was 4 (1-12). Parity did not significantly differ between the treatment groups. The median litter size $14(13-25)$ differed (Kurskal-Wallis $X^{2}=6.98, p=0.03$ ) between the treatment groups. However the difference was not significant when subjected to post hoc pairwise comparisons.

Because of varying sample sizes of the treatment groups for behavioural analysis, cortisol analysis and pathological examinations, differences in parity and litter size were tested separately for each data set. No differences were found.

\subsection{Behavioural correlations}

All the sows of the PILOT and STUDY phases of the investigation exhibited nest-building behaviour before the birth of the first piglet except for one sow of the PILOT. Six of the sows each in the PILOT and in the STUDY did not show any nest-building activity during farrowing. The median duration of performing nest-building in the 12 hours before the birth of the first piglet in the PILOT phase was in total 4 min (0-16) and in the STUDY 64 min (7- 165).

Correlations between the different behaviours before birth of the first piglet are presented in Table 5.

3.3. Comparisons between the treatment groups

\subsubsection{PILOT}

There were no differences in behaviour between the treatment groups before the birth of the first piglet.

For all the sows median DUR6 value was $85 \min (24-232 \mathrm{~min})$.

The median of 2 min of nest-building (0-64) during farrowing (DUR6) differed between the treatment groups (Kurskal-Wallis $X^{2}=11.98, n=30, p=0.04$ ). However the difference was not significant when subjected to post hoc pairwise comparisons. 


\subsubsection{STUDY}

The duration of nest-building was significantly (Kruskal-wallis $x^{2}=7.90, p=0.03$ ) longer in the newspaper group with a median of $130 \min (60-165, n=6)$ than in the wood shavings group, which had a median of $30 \min (7-121, \mathrm{n}=8)$ for the 12 hour period before the birth of the first piglet (Figure 1 a). Further, the newspaper group performed nest-building more often with a median of 220 events $(157-456, n=6)$ in the 12 hour period before the birth of the first piglet compared to the straw group $\left(x^{2}=8.5, p=0.04\right)$ with median of 126 (64- 162, $n=5)$ and wood shavings group $\left(x^{2}=7.75, p=0.03\right)$ with median of $122(39-187, n=8)$

(Figure $1 \mathrm{~b}$ ). In the $2 \mathrm{~h}$ period before the birth of the first piglet the straw group performed bar-biting significantly longer $\left(x^{2}=13.39, p<0.001\right)$ with a median of $13 \min (2-23, n=5)$ compared to the newspaper group with a median of $1 \min (0-5, n=6)$ (Figure $1 \mathrm{c})$.

Median for DUR8 was $84 \min (22-260)$. There were no differences between the groups in the behaviour DUR8 nor the duration of farrowing (DUR 8) or the duration the first piglet reached the udder.

There were six dystocic sows in the PILOT, four of them were DYS2 and three of them both DYS2 and DYS8. In the STUDY phase there were six dystocic farrowings, three of them DYS2 and three of them both had both DYS2 and DYS8. There were no differences in the occurrence of dystocia between the treatment groups nor correlations between DYS2 and DYS8 and any other parameters.

Duration and frequency of nest-building and bar-biting by hour during the $12 \mathrm{~h}$ period before birth of the first piglet in the different treatments are presented in Figure $2 \mathrm{a}-\mathrm{f}$, as well as correlations between nest-building and bar-biting behaviour for each hour (Figure $2 \mathrm{a}-\mathrm{f}$ ). No significant differences were found between the treatment groups when progression of these activities were compared by hour during the $12 \mathrm{~h}$ period before the birth of the first piglet. 


\subsection{Litter size and performance (STUDY)}

A total of 2830 piglets were born during the STUDY phase, 2509 of them were alive. Mortality is presented in table 6. Most of the deaths occur during the first days of lactation (Barnett et al., 2001), therefore the analysis was done also as two separate time periods, piglets that died earlier than 3 days of age and piglets that died on 3 days of age or later. A difference was apparent between the straw and the wood shaving groups when looking at the piglets younger than 3 days (Table 6).

In total 197 dead piglets from 66 litters were examined post mortem (Table 2), 88 piglets in the straw group, 47 in wood shavings group and 62 in newspaper group. The main causes of death were stillborn (83 piglets, $42.1 \%$ ) and crushed (50 piglets, $25.4 \%$ ). When all the crushed piglets, disregarding other findings, were analysed as one group, the number of crushed piglets was 68 (34.5\%). No statistical differences were found between the treatment groups.

Correlations between behaviours and cause of death are presented in Table 7.

Mean live weight was $1.6( \pm 0.29) \mathrm{kg}$ per piglet on day $2,1.9 \mathrm{~kg}( \pm 0.27)$ on day $4,2.3 \mathrm{~kg}( \pm 0.42)$ on day 6 and $8.7 \mathrm{~kg}( \pm 1.6)$ at weaning. There was no statistically significant differences in litter weight dues to the material treatments.

\subsection{Cortisol concentrations}

Mean salivary cortisol data are presented in Figure 3. There were no significant differences between the treatment groups.

4. Discussion

\subsection{Nest-building behaviour}

We suggest that for sows confined in farrowing crates newspaper is a more suitable material for nest-building than straw or wood shavings. On the other hand straw appeared to have a positive 
effect on piglet survival compared to the other two nest-building materials. The materials stimulated different behaviours from the sows before farrowing as follows: the newspaper group performed more nest-building activity than either the wood shavings or the straw-groups. The sows in the newspaper group also manifested less bar-biting activity before farrowing than the straw group. Our finding is supported by reports from previous studies: sows express nest-building more when suitable materials are provided (Cronin et al., 1994; Jensen, 1993; Thodberg et al., 1999) and prefer certain features for nest-building, whereas external stimuli direct the behaviour (Widowski and Curtis, 1990). Our findings might be explained by the observation that newspaper stays available at the front of the sow for longer time than wood shavings or straw. The floors of the farrowing pens were slatted, which caused wood shavings and straw to fall through. Sows also ate some of the straw, so the amount of straw that stayed available as nest-building material was less in comparison to the newspaper group.

The nest-building activity during the PILOT phase was found to be greater than previously reported by Yun et al. (2014) who observed the behaviour for 20 min every hour. The difference between our two studies could be explained by different definitions of the behaviours and different time periods of the observations. For example, Yun et al. (2014) started the observation as early as $18 \mathrm{~h}$ before farrowing and a nest-building episode was considered to start after $5 \mathrm{~s}$ of activity. The present study by contrast defined the initiation of a bout of nest-building to start after only $3 \mathrm{~s}$ of activity and also the observation period in our study started only 12 hours before the first piglet was born. The nest-building activity data in the STUDY phase were similar to earlier reports (Andersen et al., 2014; Chaloupková et al., 2014). Overall, the mean duration of nest-building activity before farrowing was lower than in the free farrowing sows in the study by Yun et al. (2014) and equal to that of the semi-confined sows in the study conducted by Chaloupková et al. (2014). This finding is therefore in line with the assumption that free farrowing sows spent more time at nest-building than did more restricted crated sows (Pastell et al., 2016).

The nest-building activities recorded for the wood shavings and straw groups did not differ significantly, which is also in line with the study by Chaloupková et al. (2014). In their study, the 
sow was able to move in one direction ("walk-around" crate) and the floors were concrete, so the nesting material did not disappear from the front of the sow as they did in the present study. The findings reported by of Chaloupková et al. (2014) and the results of our study, suggest that the functionality of both wood shavings and straw given to sows confined in farrowing crates is questionable. Chaloupková et al. (2014), however, suggested that the natural desire for nestbuilding activity can be satisfied even when a functional and or completed nest is not constructed. This suggestion, however, is contrary to the finding by Damm et al. (2003) whom reported that removal of the constructed nest is a stressor for the sow. Our finding, that sows with the newspaper as nest-building material, manifested less bar-biting behaviour, supports the finding of Damm et al. (2003) and disagrees with the Chaloupková group suggestion. Presumably, the use of newspaper as a nest-building material could have given more adequate feedback to the sow as its use by the sow resemble a more functional and complete nest in addition to newspaper itself being available for the sow longer.

A study by Petersen et al. (1990) found that the sow does not perform nest-building during farrowing when the feedback she had already received from the nest before farrowing was adequate, and this finding is also supported by Damm et al. (2000) and Thodberg et al. (1999). No differences in behaviour during parturition between the treatments were found, which is in accordance with the study of Jarvis et al. (2004) who found very little effect of straw on gilt behaviour during parturition.

\subsection{General activity: Bar-biting, nest-building, position changes}

We found no correlation between nest-building behaviour and duration that sows spent standing over the time period of 12 hours before the first piglet was born. Instead, the more often sows were standing the more often they performed bar-biting, which indicated discomfort and stress. Similar findings in total activity were presented by Cronin et al. (1993) and Mainau et al. (2010). 
The frequency of bar-biting episodes also correlated positively with the frequency of nest-building but not with duration of nest-building in our study. This indicates that the more often the sow starts a nest-building activity in a period, the more often she also performs bar-biting. It is possible when there is a lack of suitable material, that each nest-building episode is shorter in duration when the sow is not successful. This situation may lead the sow to perform bar-biting, which is considered to be redirected nest-building (Yun et al., 2015). In other words, sows try to build a nest, get frustrated when not successful and direct the nest-building behaviour to other structures of the crate.

The sows that were more in a standing position during the two hours before farrowing also performed more nest-building, which is in contrast to that found in the time period of 12 hours before the birth of first piglet. The more a sow was building a nest, the more she was in a 'bottom up' position, which was probably due to the sows attempt to reach material from outside the crate. Further, the more the sow expressed bar-biting the less time she spent in lateral recumbency. The lack of feedback from the nest starts to stress the animal increasingly as the farrowing approaches as indicated by the correlations at $2 \mathrm{~h}$ before the first piglet was born. Instead of lying down as expected (Damm et al., 2000; Jarvis et al., 1999; Jensen, 1986) the sow performs stress related behaviour. Stress shortly before farrowing can have long-term consequences: high nest-building activity during the last hours immediately before parturition leads to more nest-building during farrowing (Pedersen et al., 2006). Nest-building during farrowing is suggested to be an indicator of stress and it is reported to affect maternal behaviour later on (IIImann et al., 2015).

Prepartal behavioural observations were conducted for about 18 hours before the birth of the first piglet in most studies (Westin et al., 2015; Yun et al., 2014). The timing of nest-building and barbiting was found to be related to other behavioural aspects of the sow in the current study. Consequently the behaviour during the last couple of hours before the first piglet was born should be considered to be more indicative of stress than during the entire $18 \mathrm{~h}$ nest-building period usually observed in earlier studies. This suggestion has previously been made by Illmann et al. (2015). 
When we observed nest-building and bar-biting every hour over the 12 hour observation period we found a positive correlation in frequency of these activities during the whole time period in the newspaper group. However a positive correlation in frequency was only found at the beginning and at the end of the 12 hour period for the straw and wood shaving groups. A strong positive correlation between the mean hourly duration of nest-building and bar-biting was seen as early as six hours before the birth of the first piglet in the newspaper group. In contrast, strong correlations were found only $1-3$ hours before the expulsion of the first piglet in both the wood shavings and straw groups.

The correlations between bar-biting and nest-building was positive, probably because of the stress related factors reported in earlier studies (Vestergaard and Hansen, 1984; Yun et al., 2015). Sows that are confined in crates are not able to build a nest sufficiently even when suitable materials are provided. Sows in farrowing crates direct their behaviour at other structures more often than sows in farrowing pen (Yun et al., 2015).

It is possible that newspaper stimulated not only nest-building but also general activity of the sow, thus increased nest-building activity also increased bar-biting. Both the frequency and the duration of bar-biting was lower than nest-building for the whole 12 hour period for the newspaper group in our study. Although there was no significant change in nest-building and bar-biting intensities found, the trend of duration and frequency for bar-biting in the newspaper group decreases. By comparison we found that the trend for nest-building and bar-biting for both the wood-shavings and the straw groups increased. We conclude this might be due to newspaper allowing a more functional nest-building behaviour in sows compared to the other nest-building materials evaluated in our study.

4.3. Pathological findings and behaviour

$$
\text { 4.3.1. Mortality }
$$


The lower mortality rate found in the present study for the straw group during lactation, mainly occurred during the first days of life. This finding could be due to the effect of straw in thermoregulation of the piglets. Straw has previously been found to be more effective in decreasing mortality than shredded paper (Aumaitre and Le Dividich, 1984). Nest-building material as bedding may also enable the sow to change her the posture safely through giving the sow increased comfort and therefore avoid crushing the piglets (Herskin et al., 1998; Pedersen et al., 2006). However these qualities of straw probably did not affect the mortality in our study, since the amount supplied was small and it was given in front of the sow on the slats. Some of the straw was also eaten by the sow. Oliviero et al. (2009) previously noted that fibre affects the intestinal activity of the sow, which might positively affect the periparturient performance positively. Increased fibre in the diet also lead to more water consumption (Oliviero et al., 2009) and higher water consumption, in turn, enhances milk production. A study by Cronin and Smith (1992) found that piglets in pens with straw suckled more than piglets of crated sows without straw. The fibre content of the diet also affects the colostrum composition (Krogh et al., 2015). Weight gain of the piglets in the present study showed a similar pattern to those reported in an earlier study (Cronin and Smith, 1992) and no significant difference in the piglet weight gain was found between the treatments of the present study. The presence of straw, even in small amounts, might have influenced maternalcare and immune competence of piglets arising from earlier and increased colostrum intake, which might be expected to enhance piglet health and survival.

\subsubsection{Crushing}

The frequency of sternal and lateral positions at two hours before the first expulsion of the farrowing and piglet crushing correlated negatively. Moreover the more sows sat and performed bar-biting before the birth of the first piglet the less piglets were crushed. It is known that during the prepartum period sows that do not crush their piglets move more and perform more nest-building compared to sows that do crush their piglets (Andersen, 2005; Thodberg et al., 1999). Therefore, we suppose that these correlations indicate an ease of changing position with high levels of 
general activity. A higher state of general activity allows the sow to avoid crushing, despite experiencing stress because of restriction of movement in the crate (see section 4.2.).

\subsubsection{Stillborn}

In the present study higher nest-building activity at 12 hours before the birth of the first piglet was related to a decreased in the number of stillborn piglets. Furthermore, increased lateral laying, which can be interpreted as low activity during nest-building, correlated positively with stillborn rate. Low nest-building activity is associated with lower piglet survival due to delayed births (Baxter, 1983). We found no statistical differences in periparturient piglet survival between the treatments in our study, which is in line with that reported by Cronin et al. (1994), but is contrary to findings reported by Cronin et al. (1993) and Westin et al. (2015). Even though nest-building activity was higher in the newspaper group in our study, the difference was possibly not big enough to affect the sow's oxytocin status, and thus farrowing success, and consequent improvement on piglet survival.

\subsection{Salivary cortisol concentrations}

The course of cortisol concentration in our study agrees with previously presented data (Lawrence et al., 1994; Oliviero et al., 2008). We did not find significant differences in cortisol levels between the groups during the whole experimental period.

\section{Conclusion}

Different nest-building materials stimulate sow behaviour differently before farrowing. More specifically sows seem to benefit more from newspaper than straw or wood shavings. Offering suitable nest-building material, even to sows confined in farrowing crates where the possibility to perform nest-building is limited, leads to higher nest-building activity. It is known that nest-building 
before farrowing results in favourable changes in sow behaviour and maternal characteristics.

However, it seems that the sow is still not able to fulfil the behavioural need of nest-building in the confines of a crate fully using any of the materials provided in our present study, because all sows showed frequent bar-biting behaviour. In the future, therefore, more attention should be paid to the characteristics of the bedding materials offered for nest-building in piggeries in which the sows are confined in farrowing crates.

\section{Acknowledgements}

This project was funded by the Finnish Ministry of Agriculutre (project number 2906/502/2008) and further supported by a grant from the Mercedes-Zacharias Research Foundation. The authors would like to thank the staff of Saparola Oy piggery for their remarkable assistance and support in this research. Special thanks to Taina and Jukka Kalliotiura for offering their facilities to the research group, to Merja Pöytäkangas for her laboratory analysis, Antti Flyckt for his technical support, veterinary students Mikaela Sauvala and Sanna Malkamäki for their efforts in the piggery and to veterinary student Minna Päivärinta for participating in the data analysis. 
References

Algers, B., Uvnäs-Moberg, K., 2007, Maternal behavior in pigs. Hormones and behavior, 52, 78 85.

Andersen, I.L., 2014. Nest building and posture changes and activity budget of gilts housed in pens and crates. Applied Animal Behaviour Science, 159, 29- 33.

Andersen, I.L., 2005. Crushing of piglets by the mother sow (Sus scrofa) - Purely accidental or a poor mother?. Applied Animal Behaviour Science, 93, 229 - 243.

Arey, D.S., 1997. Behavioural observations of peri-parturient sows and the development of alternative farrowing accommodation: a review. Animal Welfare, 6, $217-229$.

Aumaitre, A., Le Dividich, J., 1984. Improvment of piglet survival rate in relation to farrowing systems and conditions. Annales de Recherches Vétérinaires, INRA editions, 15, 173 - 179.

Barnett, J.L., Hemsworth, P.H., Cronin, G.M., Jongman, E.C, Hutson, G.D., 2001. A review of the welfare issues for sows and piglets in relation to housing. Australian Journal of Agricultural Research. 52, 1-28.

Baxter, M.R., 1983. Ethology in environmental design for animal production. Applied Animal Ethology, vol. 9, $207-220$.

Burri, M., Wechsler, B., Gygax, L., Weber, R., 2009. Influence of straw length, sow behaviour and room temperature on the incidence of dangerous situations for piglets in a loose farrowing system. Applied Animal Behaviour Science, 117, 181 - 189.

Castrén, H., Algers, B., de Passillé, A., Rushen, J., Uvnäs-Moberg, K., 1993. Preparturient variation in progesterone, prolactin, oxytocin and somatostatin in relation to nest building in sows. Applied Animal Behaviour Science, 38, 91-102. 
Chaloupková, H., Illmann, G., Neuhauserová, K., Šimečková, M., Kratinová, P, 2014. The effect of nesting material on the nest-building and maternal behavior of domestic sows and piglet production, 89, 531-537.

Cronin, G.M., Schirmer, B.N., McCallum, T.H., Smith, J.A., Butler, K.L., 1993. The Effects of providing sawdust to pre-parturient sows in farrowing crates on sow behaviour, the duration of parturition and the occurrence of intra-partum stillborn piglets. Applied Animal Behaviour Science, $36,301-315$.

Cronin, G.M., Smith, J.A., 1992. Suckling behaviour of sows in farrowing crates and straw-bedded pens, Applied Animal Behaviour Science, 33, 175 - 189.

Cronin, G.M., Smith, J.A., Hodge, F.M, Hemsworth, P.H. 1994. The behaviour of primiparous sows around farrowing in response to restraint and straw bedding. Applied Animal Behaviour Science, $39,269-280$.

Council of the European Union, council directive 2008/120/EC, 2008. Laying down minimum standards for the protection of pigs. http://eur-lex.europa.eu/legalcontent/EN/ALL/?uri=CELEX\%3A32008L0120 (referenced 28.6.2017)

Damm, B.I., Lisborg, L., Vestergaard, K.S., Vanicek, J., 2003. Nest-building, behavioural disturbances and heart rate in farrowing sows kept in crates and Schmid pens. Livestock Production Science, 80, 175 - 187.

Damm, B.I., Pedersen, L.J., Heiskanen, T., Nielsen, N.P., 2005. Long-stemmed straw as an additional nesting material in modified Schmid pens in a commercial breeding unit: effects on sow behaviour, and on piglet mortality and growth. Applied Animal Behaviour Science, 92, 45 - 60 .

Damm, B.I., Pedersen, L.J., Marchant-Forde, J.N., Gilbert, C.L., 2003. Does feed-back from a nest affect periparturient behaviour, heart rate and circulatory cortisol and oxytocin in gilts?, Applied Animal Behaviour Science,83, pp. 55 - 76. 
Damm, B.I., Vestergaard, K.S., Schrøder-Petersen, D.L, Ladewig, J., 2000. The effects of branches on prepartum nest building in gilts with access to straw. Applied Animal Behaviour Science, 69, $113-124$.

Herskin, M.S., Jensen, K.H., Thodberg, K., 1998. Influence of environmental stimuli on maternal behaviour related to bonding, reactivity and crushing of piglets in domestic sows. Applied Animal Behaviour Science, 58, $241-254$.

Hulsen, J., Scheepens, K., 2006. Becoming pregnant, Determining condition in: Hulsen, J., van der Woude, M. (Eds.), Pig Signals. Roodbont B. V., Netherlands, pp. 61

Illmann, G., Chaloupkova, H., Neuhauserova, K., 2015. Effect of pre- and post-partum sow activity on maternal behaviour and piglet weight gain $24 \mathrm{~h}$ after birth. Applied Animal Behaviour science, $163,80-88$

Janssens, C.J.J.G., Helmond, F.A.,Weigant, V.M., 1995. The effect of chronic stress on plasma cortisol concentrations in cyclic female pigs depends on the time of day. Domestic Animal Endocrinology, 12, $167-177$.

Jarvis, S., Reed, B.T., Lawrence, A.B., Calvert, S.K., Stevenson, J., 2004. Peri-natal environmental effects on maternal behaviour, pituitary and adrenal activation, and the progress of parturition in the primiparous sow. Animal Welfare, 13, 171-181.

Jarvis, S., McLean, K.A., Calvert, S.K., Deans, L.A., Chirnside, J., Lawrence, A.B., 1999. The responsiveness of sows to their piglets in relation to the length of parturition and the involvement of endogenous opioids. Applied Animal Behaviour Science, 63, 195 - 207.

Jarvis, S., Van der Vegt, B.J., Lawrence, A.B., McLean, K.A., Deans, L.A., Chirnside, J., Calvert, S.K., 2001. The effect of parity and environmental restriction on behavioural and physiological responses of pre-parturient pigs. Applied Animal Behaviour Science, 71, $203-216$.

Jensen, P., 1986. Observations on the maternal behaviour of free ranging domestic pigs. Applied Animal Behavioiur Science,16, 131-142. 
Jensen, P., 1993. Nest building in domestic sows: the role of external stimuli. Animal Behaviour, $45,351-358$.

Johnson, A., Marchant-Forde, J., 2009. Welfare of pigs in farrowing environment, in: MarchantForde, J. (ed.), Welfare of pigs. Springer, Netherlands, pp. 141-188.

Krogh, U., Bruun, T., Amdi, C., Flummer, C., Poulsen, J, Theil, P., 2015. Colostrum production in sows fed different sources of fiber and fat during late gestation, Canadian Journal of Animal Science, 95, $211-223$.

Lammers, G.J., De Lange, A., 1986. Pre- and post-farrowing behaviour in primiparous domesticated pigs. Applied Animal Behaviour Science, 15, 31-43.

Lawrence, A.B., Petherick, J.C., McLean, K.A., Deans, L.A., Chirnside, J., Gaughan, A., Clutton, E., Terlouw, E.M.C., 1994. The effect of environment on behaviour, plasma cortisol and prolactin in parturient sows, Applied Animal Behaviour Science, 39, 313-330.

Mainau, E., Dalmau, A., Ruiz-de-la-Torre, J.L., Manteca, X., 2010. A behavioural scale to measure ease of farrowing in sows. Theriogenology, 74, $1279-1287$.

Ministry of Agriculture and Forestry in Finland 2012, 2012. Statute 629/2012 Valtioneuvoston asetus sikojen suojelusta. http://www.finlex.fi/fi/laki/ajantasa/2012/20120629 (referenced 28.6.2017)

Oliviero, C., Heinonen, M., Valros, A., Hälli, O., Peltoniemi, O.A.T., 2008. Effect of the environment on the physiology of the sow during late pregnancy, farrowing and early lactation. Animal Reproduction Science, 105, $365-377$.

Oliviero, C., Kokkonen, T., Heinonen, M., Sankari, S., Peltoniemi, O. 2009. Feeding sows with high fibre diet around farrowing and early lactation: Impact on intestinal activity, energy balance related parameters and litter performance. Research in Veterinary Science, 86, $314-319$. 
Otten, W., Kanitz, E., Couret, D., Veissier, I., Prunier, A., Merlot, E., 2010. Maternal social stress during late pregnancy affects hypothalamic-pituitary-adrenal function and brain neurotransmitter systems in pig offspring. Domestic animal endocrinology, 38, 146 - 156.

Otten, W., Puppe, B., Stabenow, B., Kanitz, E., Schön, P.C., Brüssow, K.P., Nürnberg, G., 1997. Agonistic interactions and physiological reactions of top- and bottom-ranking pigs confronted with a familiar and an unfamiliar group: Preliminary results. Applied Animal Behaviour Science, 55, 79 90.

Pastell, M., Hietaoja, J., Yun, J., Tiusanen, J., Valros, A. 2016. Predicting farrowing of sows housed in crates and pens using accelerometers and CUSUM charts. Computers and Electronics in Agriculture, 127, $197-203$.

Pedersen, L.J., Damm, B.I., Marchant-Forde, J.N., Jensen, K.H., 2003. Effects of feed-back from the nest on maternal responsiveness and postural changes in primiparous sows during the first 24 h after farrowing onset. Applied Animal Behaviour Science, 83, 109- 124.

Pedersen, L.J., Jorgensen, E., Heiskanen, T., Damm, B.I. 2006. Early piglet mortality in loosehoused sows related to sow and piglet behaviour and to the progress of parturition. Applied Animal Behaviour Science, 96, $215-232$.

Petersen, V., Recén, B., Vestergaard, K., 1990. Behaviour of sows and piglets during farrowing under free-range conditions. Applied Animal Behaviour Science, 26, 169 - 179.

Thodberg, K., Jensen, K.H., Herskin, M.S., 2002. Nest building and farrowing in sows: Relation to the reaction pattern during stress, farrowing environment and experience. Applied Animal Behaviour Science, 77, $21-42$.

Thodberg, K., Jensen, K.H., Herskin, M.S., Jørgensen, E., 1999.Influence of environmental stimuli on nest building and farrowing behaviour in domestic sows. Applied Animal Behaviour Science, 63, $131-144$. 
van Dijk, A.J., van Rens, B.T.T.M., van der Lende, T., Taverne, M.A.M., 2005. Factors affecting duration of the expulsive stage of parturition and piglet birth intervals in sows with uncomplicated, spontaneous farrowings. Theriogenology, 64, $1573-1590$.

Vestergaard, K.S., Hansen, L.L., 1984. Tehtered versus loose sows: Ethological observations and measures of productivity. I. Ethological observations during pregnancy and farrowing. Annales de Recherches Vétérinaires, 15, $245-256$.

Westin, R., 2014. Strategic Use of Straw at Farrowing, Effects on Behaviour, Health and Production in Sows and Piglets, Swedish Universtiy of Agricultural Sciences, Skara.

Westin, R., Holmgren, N., Hultgren, J., Ortman, K., Linder, A., Algers, B., 2015. Post-mortem findings and piglet mortality in relation to strategic use of straw at farrowing. Preventive veterinary medicine, 119, $141-152$.

Westin, R., Hultgren, J., Algers, B., 2015. Strategic use of straw increases nest building in loose housed farrowing sows. Applied Animal Behaviour Science, 166, 63 - 70.

Widowski, T.M., Curtis, S.E., 1990. The influence of straw, cloth tassel, or both on the prepartum behavior of sows. Applied Animal Behaviour Science, 27, 53 - 71.

Yun, J., Swan, K.M., Farmer, C., Oliviero, C., Peltoniemi, O., Valros, A., 2014. Prepartum nestbuilding has an impact on postpartum nursing performance and maternal behaviour in early lactating sows. Applied Animal Behaviour Science, 160, 31 - 37.

Yun, J., Swan, K., Oliviero, C., Peltoniemi, Valros, A., 2015. Effects of prepartum housing environment on abnormal behaviour, the farrowing process, and interactions with circulating oxytocin in sows. Applied Animal Behaviour Science, 162, $20-25$.

Yun, J., Swan, K., Vienola, K., Farmer, C., Oliviero, C., Peltoniemi, O., Valros, A., 2013. Nestbuilding in sows: Effects of farrowing housing on hormonal modulation of maternal characteristics. Applied Animal Behaviour Science, 148, 77 - 84. 
Figure 1 a-c Nest-building frequency (a) and duration (b) over 12 hours, and bar-biting for 2 hours (c) before the first piglet was born. The error bars lacking common letters differ significantly $(p<$ $0.05)$.
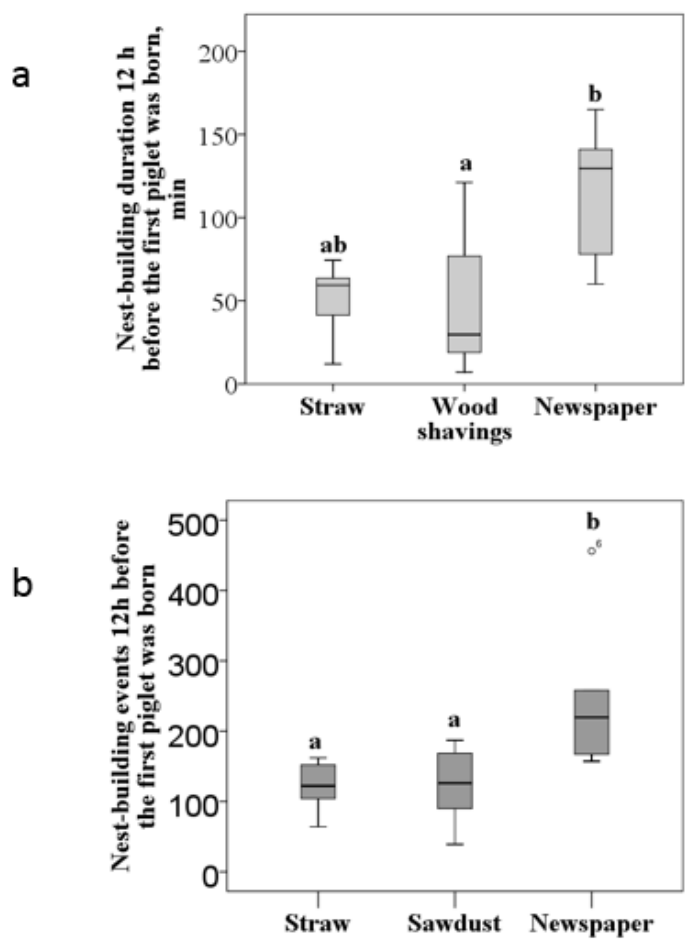

c

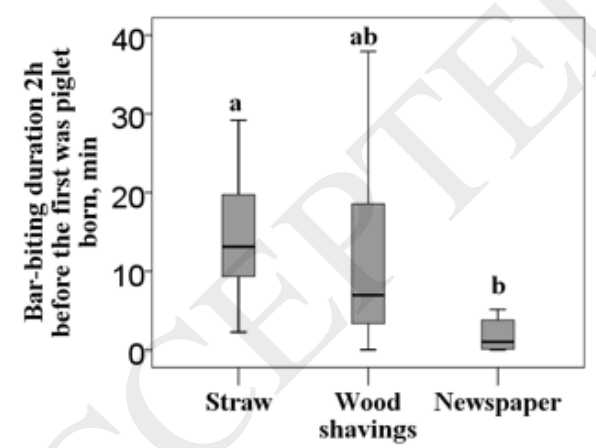


Figure 2 a-f Nest-building and bar-biting frequencies $(a-c)$ and durations $(d-f)$ of the three treatments (straw $n=5$, wood shavings $n=8$, newspaper $n=6$ ) 12 hours before the first piglet was born. Significant correlations between bar-biting and nest-building behaviour $(p<0.05)$ in which the correlations strength is $0.5-1.0$ are indicated by arrows, thus $0.6=\uparrow \uparrow, \geq 0.7=\uparrow \uparrow \uparrow$.

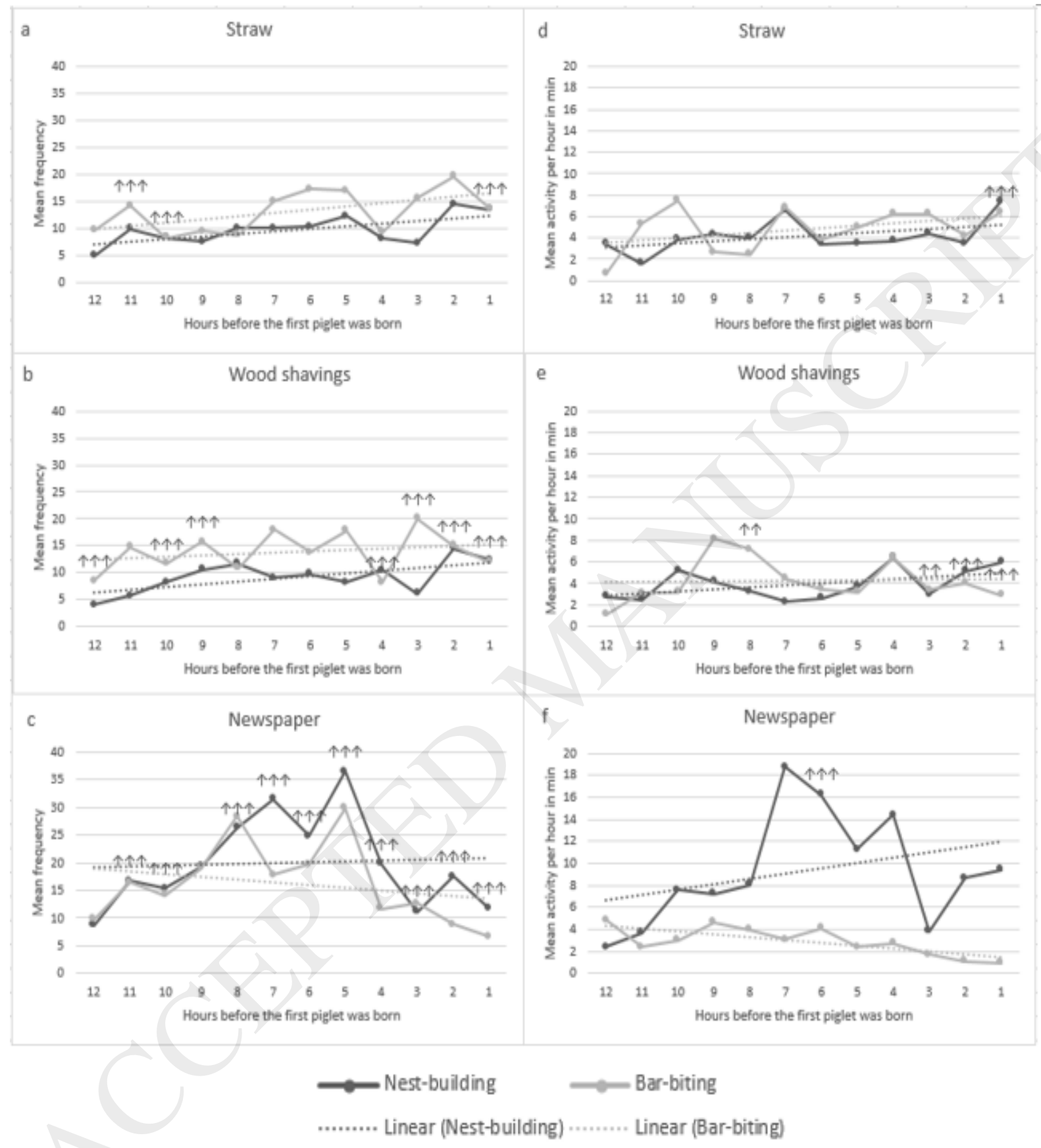


Figure 3 Mean salivary cortisol concentration, day 0 is the day of farrowing. Results are given as means and the error bars depict standard deviations. $n=47$.

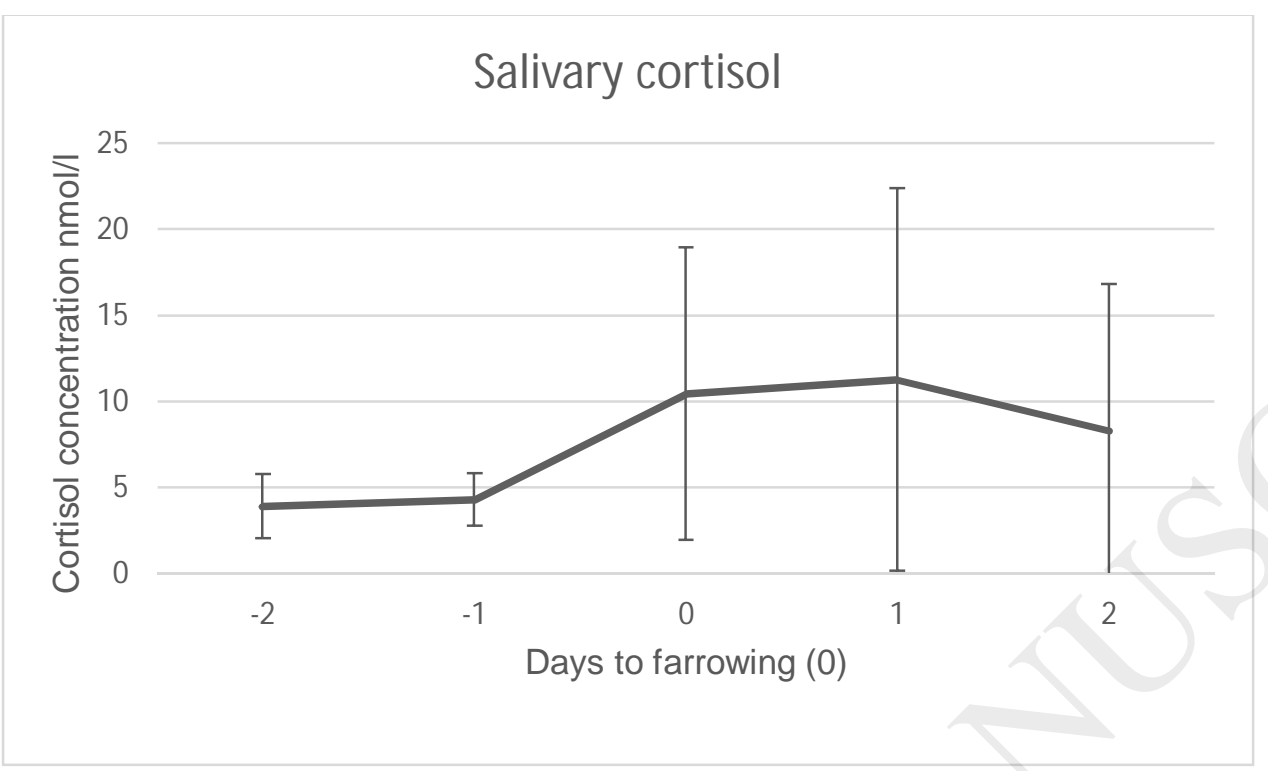


Table 1 Description of materials given to sows for nest-building in both the pilot study and the main study. In the main study wood shavings, straw and newspaper were used. The treatment groups were object on the ground, object on the side, wood shavings, straw, shredded paper while newspaper served as the control.

\begin{tabular}{|l|l|l|}
\hline Treatment group & Description & Amount provided daily \\
\hline $\begin{array}{l}\text { Object on the ground } \\
\text { Object on the floor }\end{array}$ & $\begin{array}{l}\text { Object, bovine tannage (Tärnsjö } \\
\text { Garveri, Sweden), Sisal rope } \varnothing 1 \\
\text { cm (Piippo oy, Finland) }\end{array}$ & $\begin{array}{l}\text { 1 object attached in to the crate in } \\
\text { front of or to the side of the sow } \\
\text { about } 50 \mathrm{~cm} \text { above the floor (Picture } \\
1)\end{array}$ \\
\hline Wood shavings & $\begin{array}{l}\text { Wood shavings, coniferous (made } \\
\text { at the farm) }\end{array}$ & $2-3$ I in front of the sow \\
\hline Straw & $\begin{array}{l}\text { Straw, chopped, wheat (made at } \\
\text { the farm) }\end{array}$ & $2-3$ I in front of the sow \\
\hline Shredded paper & $\begin{array}{l}\text { Shredded paper, made out of } \\
\text { recycled paper, } 2-5 \mathrm{~cm} \times 30 \mathrm{~cm} \\
\text { pieces }\end{array}$ & $2-3$ I in front of the sow \\
\hline Newspaper & $\begin{array}{l}\text { Newspaper (Helsingin Sanomat, } \\
\text { Sanoma media, Finland) }\end{array}$ & $3-6$ full or half pages \\
\hline
\end{tabular}


Table 2 Sample sizes for different parameters for six treatment groups; object on the ground, object on the side, straw, shredded paper, wood shavings and newspaper. The behaviour of the sow over two periods was observed and analyzed: ${ }^{1}$ before birth of the first piglet and ${ }^{2}$ during the birth of the first six piglets (PILOT) or ${ }^{3}$ during the birth of the first eight piglets (STUDY). Other parameters measured were salivary cortisol (Cortisol), piglet mortality (Mortality), piglet weight gain on days 2, 4, 6 and at weaning (Weight) and post mortem examination of piglets that died

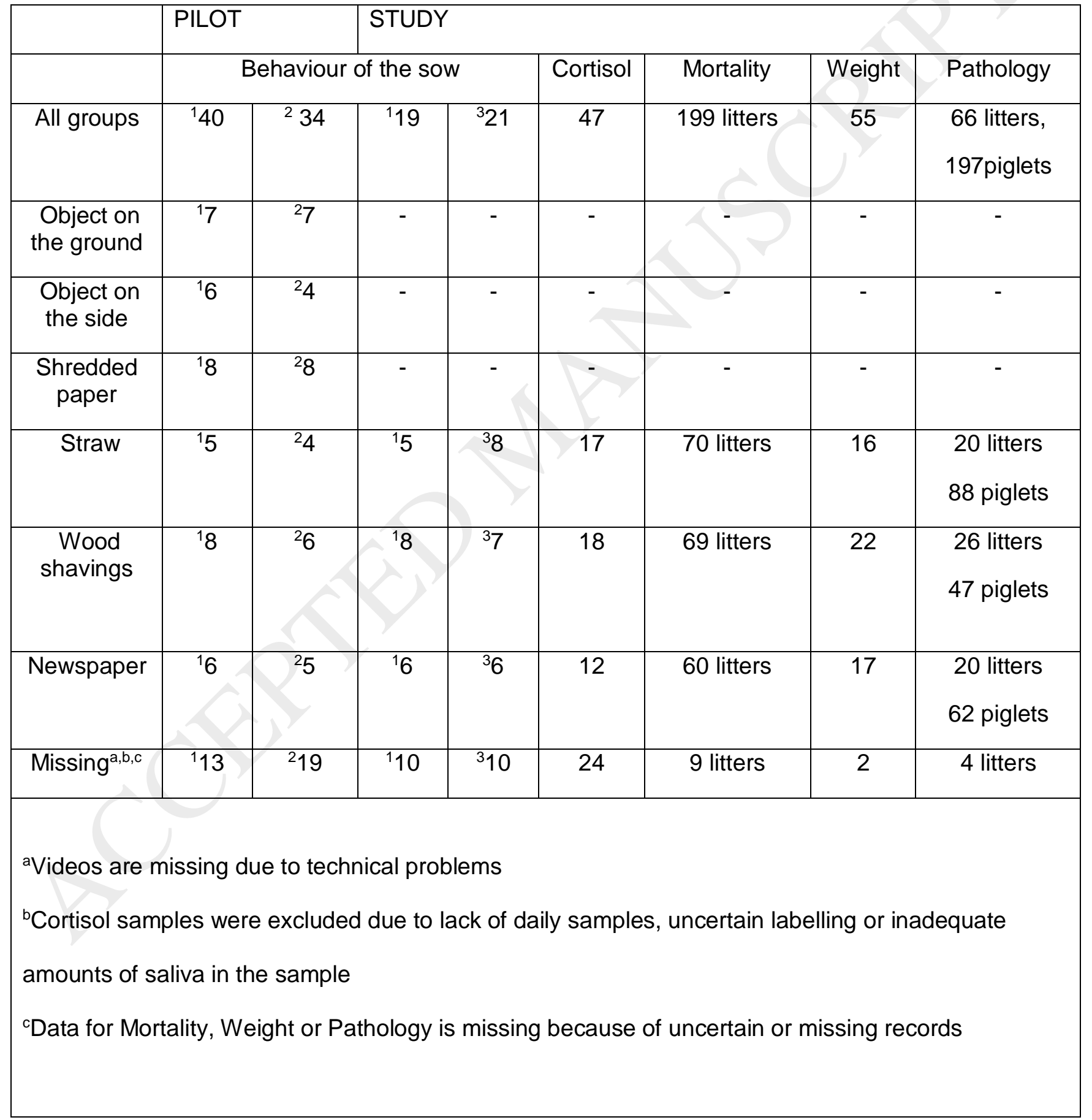


Table 3 Pathological examination criteria and causes of death of piglets that died during the study

\begin{tabular}{|l|l|}
\hline Cause of death & Pathological findings \\
\hline Stillborn & Lungs sink in water \\
\hline Cahectic & Stomach empty, intestine empty \\
\hline Crushed & $\begin{array}{l}\text { Accumulation of tissue fluid under the skin, hematomas, } \\
\text { broken bones }\end{array}$ \\
\hline Infection, sepsis & $\begin{array}{l}\text { Fibrinous liquid in body cavities, fibrin in organs, other } \\
\text { changes in organs such as pus, petechial haemorrhage }\end{array}$ \\
\hline $\begin{array}{l}\text { Other reason / } \\
\text { Undefined }\end{array}$ & $\begin{array}{l}\text { No visible pathological changes found, } \\
\text { post mortem changes too developed, } \\
\text { other signs such as anaemia, malformation }\end{array}$ \\
\hline
\end{tabular}


Table 4 Definition of the sow postures and behaviours (modified from Andersen,2014; Burri, 2009;

Chaloupková, 2014; Damm, 2003; Thodberg,1999, 2002). Each behaviour was interpreted to start and stop after $3 \mathrm{~s}$ of continuous/discontinuous activity.

\begin{tabular}{|l|l|}
\hline Behaviour & Description \\
\hline Sitting & Both front legs are straight, sows posterior touches the ground \\
\hline Standing & Sow stands on all four feet \\
\hline Bottom up & Soth front knees touch the ground, hind legs are extended \\
\hline Lying sternally & $\begin{array}{l}\text { Sow lies with the udder exposed, head, hip bone and shoulder are } \\
\text { in contact with the ground }\end{array}$ \\
\hline Lying laterally & $\begin{array}{l}\text { Pawing: Sow paws with front foot } \\
\text { Rooting/Arranging: Sow roots with the snout the material available } \\
\text { or floor } \\
\text { Pushing the body into the nest: Sow lies down slowly while the } \\
\text { head is being moved from side to side }\end{array}$ \\
\hline Nest-building & $\begin{array}{l}\text { Sow bites or roots structures or objects which are not nest building } \\
\text { materials }\end{array}$ \\
\hline Bar-biting & \begin{tabular}{l} 
Time from first piglet born until any piglet accesses to the teat \\
\hline First teat contact
\end{tabular} \\
\hline
\end{tabular}


Table 5 Prepartal behavioural correlations at 12 hours $^{a}$ and 2 hours $^{b}$ before the birth of the first piglet. Only significant results $(p<0.05)$ detected in both parts, the PILOT and the STUDY, and for which the correlation strength is $0.5-1.0(0.5=\uparrow, 0.6=\uparrow \uparrow, 0.7 \geq \uparrow \uparrow \uparrow)$ are shown. Frequencies are indicated by $F$ and duration by D. For the PILOT $n=40$ and the STUDY $n=19$.

\begin{tabular}{|c|c|c|c|c|}
\hline & $\begin{array}{c}\text { Nest-building } \\
\text { D }\end{array}$ & $\begin{array}{c}\text { Nest-building } \\
\mathrm{F}\end{array}$ & $\begin{array}{c}\text { Lateral } \\
\text { position D }\end{array}$ & $\begin{array}{c}\text { Standing } \\
\text { position F }\end{array}$ \\
\hline Bottom up position D & $\uparrow^{b}$ & & & \\
\hline Standing position $\mathrm{F}$ & $\uparrow \uparrow^{b}$ & $\uparrow \uparrow^{b}$ & & \\
\hline Standing position D & $\uparrow \uparrow \uparrow b$ & $\uparrow \uparrow^{b}$ & & \\
\hline Bar biting $\mathrm{F}$ & & $\uparrow \uparrow \uparrow^{a} \uparrow \uparrow^{b}$ & $\downarrow^{b}$ & $\uparrow^{a}$ \\
\hline Bar biting $\mathrm{D}$ & & $\uparrow \uparrow^{b}$ & & \\
\hline
\end{tabular}


Table 6 Mortality of piglets in the STUDY phase during five time periods: all piglets that died during the entire lactation period, including pre- and intrapartal deaths (All, stillbirths included); all piglets that died during the entire lactation period excluding prepartal and intrapartal deaths (All, stillbirths excluded); pre- or intrapartum mortality (Stillborn); piglets that died during the first 3 days of lactation; and piglets that died later than three days of lactation. Comparisons between the treatment groups was done using the percentage of dead piglets from liveborn piglets ${ }^{1}$ or all piglets born $^{2}$. Values within a row lacking common letters differ $\left(p<0.05\right.$, signed as $\left.{ }^{*}\right)$, Min $=$ minimum, Max $=$ maximum

\begin{tabular}{|c|c|c|c|c|c|c|c|c|}
\hline & $\begin{array}{l}\mathrm{n} \\
\text { piglets }\end{array}$ & $\begin{array}{l}\% \text { of all } \\
\text { piglets } \\
\text { born }\end{array}$ & $\begin{array}{l}\% \text { of } \\
\text { live } \\
\text { born }\end{array}$ & $\begin{array}{l}\% \text { of all } \\
\text { dead }\end{array}$ & $\begin{array}{l}\text { Straw } \\
\text { (median, } \\
\text { range) }\end{array}$ & $\begin{array}{l}\text { Wood } \\
\text { shavings } \\
\text { (median, } \\
\text { range) }\end{array}$ & $\begin{array}{l}\text { Newspaper } \\
\text { (median, } \\
\text { range) }\end{array}$ & $p$ value \\
\hline $\begin{array}{l}\text { All, stillbirths } \\
\text { included }\end{array}$ & 520 & 22 & - & - & $\begin{array}{c}12 \\
0-71^{a}\end{array}$ & $\begin{array}{c}17 \\
0-60^{a}\end{array}$ & $\begin{array}{c}18 \\
0-60^{a}\end{array}$ & 0.07 \\
\hline $\begin{array}{l}\text { All, stillbirths } \\
\text { excluded }\end{array}$ & 199 & 7 & 8 & 38 & $\begin{array}{c}{ }^{1} 0 \\
0-50^{a}\end{array}$ & $\begin{array}{c}18 \\
0-38^{b}\end{array}$ & $\begin{array}{c}17 \\
0-50^{b}\end{array}$ & $0.00^{*}$ \\
\hline Stillborn & 321 & 11 & 13 & 62 & $\begin{array}{c}27 \\
0-71^{a}\end{array}$ & $\begin{array}{c}27 \\
0-54^{a}\end{array}$ & $\begin{array}{c}{ }^{2} 8 \\
0-57^{a}\end{array}$ & 0.8 \\
\hline $\begin{array}{l}\text { First } 3 \text { days } \\
\text { of lactation }\end{array}$ & 150 & 5 & 6 & 29 & $\begin{array}{c}10 \\
0-30^{b}\end{array}$ & $\begin{array}{c}{ }^{1} 6 \\
0-25^{a}\end{array}$ & $\begin{array}{c}13 \\
0-40^{a}\end{array}$ & $0.00^{*}$ \\
\hline $\begin{array}{l}\text { Later than } 3 \\
\text { days of } \\
\text { lactation }\end{array}$ & 49 & 2 & 2 & 9 & $\begin{array}{c}10 \\
0-17^{a}\end{array}$ & $\begin{array}{c}{ }^{1} 0 \\
0-18^{a}\end{array}$ & $\begin{array}{c}{ }^{1} 0 \\
0-17^{a}\end{array}$ & 0.08 \\
\hline
\end{tabular}


Table 7 Correlations between the cause of death and behaviour during 12 hours and during 2 hours before the birth of the first piglet and during the birth of the first eight piglets. Only significant results $(p<0.05)$ in which the correlations strength is $0.5-1.0$ are shown $(0.5=\uparrow, 0.6=\uparrow \uparrow, 0.7 \geq$ $\uparrow \uparrow \uparrow)$.

\begin{tabular}{|l|l|l|}
\hline Behaviour & $\begin{array}{l}\text { Crushed, } \\
\% \text { of } \\
\text { liveborn }\end{array}$ & $\begin{array}{l}\text { Stillborn, } \\
\text { \% of all piglets } \\
\text { born }\end{array}$ \\
\hline 12 hours before first piglet born & & $\downarrow$ \\
\hline Nest-building duration, min & & $\downarrow \downarrow$ \\
\hline Nest-building frequency, $\mathrm{n}$ & & $\uparrow \uparrow$ \\
\hline Laying laterally, duration, min & & \\
\hline Sitting, duration, min & $\downarrow \downarrow$ & \\
\hline 2 hours before first piglet born & & \\
\hline Lying sternally frequency, $\mathrm{n}$ & $\downarrow$ & \\
\hline Sitting, frequency, $\mathrm{n}$ & $\downarrow$ & \\
\hline Bar-biting, duration min & $\downarrow \downarrow$ & \\
\hline Sitting, duration, min & $\downarrow \downarrow$ & \\
\hline During pulsation & & \\
\hline Lying laterally frequency, $\mathrm{n}$ & $\downarrow$ & \\
\hline Bar-biting, duration, min & $\downarrow \downarrow$ & \\
\hline
\end{tabular}

